10. Severynova M. (2012) Second Concerto for Piano and Orchestra by Miroslav Skoryk in the Context of Archetypal Images of the Sacred. Journal of Tchaikovsky National Music Academy of Ukraine. Kyjiv, (№ 4 (17)), P. 93-104. [in Ukrainian]. 11. Schweitzer A. (1965) Johann Sebastian Bach. M.: Muzyka [in Russian]. 12. Javorskiy B. (1972) Articles, memories, letters. M.: Sov. kompozitor [in Russian].

Стаття надійция до редакції 12.04.2017

УДК $78.03+782.1$

Арутюнян Гаянэ Хачиковна

преподаватель кафедры сольного пения

Одесской национальной музыкальной

академии имени А. В. Неждановой

odma_n@ukr.net

\title{
ДИАЛОГ ТРАДИЦИЙ В ОПЕРЕ А. ТИГРАНЯНА «АНУШ»
}

Цель исследования - выявить синтез национального мышления и европейских принципов оперного формообразования в раннем армянском оперном творчестве. Научная новизна состоит в применении специфического ракурса анализа оперы А. Тиграняна «Ануш». Методологическая основа исследования заключается в диалогическом подходе и опирается на преломление концепции диалога М. Бахтина в научных исследованиях А. Самойленко и Бай Цюаня. Выводы. Художественный синтез, осуществленный А. Тиграняном в опере «Ануш», представляется как некоторое коммуницирующее явление двух противоположных традиций, двух типов музыкально-художественного мышления, которое можно охарактеризовать одновременно как диалог согласия, проявляющийся как отношение композитора к традиционному пониманию армянской культуры, и диалог разногласия, благодаря которому композитор смог привлечь ранее нетипичные для авторского мышления А. Тиграняна принципы оперной архитектоники и драматургической организации музыкального материала.

Ключевые слова: традиция, диалог, художественный синтез, национальное мышление, армянская профессиональная музыка, А. Тигранян, опера «Ануш». 
Arutyunyan Gayane, teacher of department of solo singing, Odessa National A. V. Nezhdanova Academy of Music

Dialogue of traditions in the opera by A. Tigranyan «Anush»

Research objective is revealing of synthesis of national thinking and the European principles of opera shaping in early Armenian opera works. The scientific novelty consists in application of a specific foreshortening of the analysis of the opera of A. Tigranyan of "Anush». The methodological basis of a research consists in dialogical approach and A. Samoylenko and Bai of Quan relies on refraction of the concept of dialogue of M. Bakhtin in scientific research. Conclusions. The art synthesis which is carried out by A. Tigranyan in the opera of Anush is represented as some communicating phenomenon of two opposite traditions, two types musical and art thinking which can be characterized at the same time as consent dialogue which is shown as the composer's attitude towards traditional understanding of the Armenian culture and dialogue of disagreement thanks to which the composer could attract earlier atypical to A. Tigranyan author's thinking principles of opera architectonics and dramaturgic organization of musical material.

Keywords: tradition, dialogue, art synthesis, national thinking, Armenian professional music, A. Tigranyan, opera of Anush.

Арутюнян Гаяне Хачіківна, викладач кафедри сольного співу Одеської національної музичної академії імені А. В. Нежданової

Діалог традищій в опері А. Тиграняна «Ануш»

Мета дослідження - виявити синтез національного мислення та європейських приниипів оперного формотворення у ранній вірменській оперній творчості. Науковою новизною $є$ застосування специфічного ракурсу аналізу опери А. Тиграняна «Ануш». Методологічна основа дослідження полягає в діалогічному підході та спирається на переломлення концепції діалогу М. Бахтіна в наукових дослідженнях А. Самойленко і Бай Цюаня. Висновки. Художній синтез, здійснений А. Тиграняном в опері «Ануш», представляється як комунікативне явище двох протилежних традицій, двох типів музично-художнього мислення, яке можна охарактеризувати одночасно як діалог згоди, що виявляється як відношення композитора до традиційного розуміння вірменської культури, і діалог розбіжності, завдяки якому композитор зміг залучити раніше нетипові для авторського мислення А. Тиграняна принципи оперної архітектоніки і драматургічної організації музичного матеріалу.

Ключові слова: традиція, діалог, художній синтез, національне мислення, вірменська професійна музика, А. Тигранян, опера «Ануш».

Актуальность работы и анализ публикаций. Армянская музыка второй половины XX столетия получила широкое освещение в музыковедческих и культурологических исследованиях. Профессиональное творчество, стремительно развивающееся в послевоенные годы XX 
столетия, становится явлением интегративного характера, включающим множество актуальных и развитых композиторских техник и стилей, имеющих мощную историческую основу, национальную интонационную традицию и художественное мышление. Данному явлению посвящены исследовательские труды С. Саркисян «Интегрирующие процессы в армянской музыке» [7], «Армянская музыка в контексте XX века» [8], К. Авдалян «Национальный стиль в армянской музыкальной культуре XX века» [1].

Существуют современные музыковедческие исследования, которые касаются вопросов симфонической сферы творчества композиторов Армении, в частности диссертационное исследование Ж. Зурабян «Национальное своеобразие тематизма в армянской симфонической музыке первых послевоенных лет» [5].

Армянской музыке раннего периода XX столетия посвящены труды представителей советской музыковедческой школы, среди них назовем работы Г. Тигранова «Армянский музыкальный театр», [9] А. Шавердяна «Очерки по истории армянской музыкти XIX - XX веков. Досоветский период». [11].

Тем не менее, период становления профессионального композиторского творчества Армении стал интересным художественным явлением, которое требует нового, более современного подхода в его изучении, с привлечением междисциплинарных актуальных исследовательских позиций.

Цель исследования - выявить синтез национального мышления и европейских принципов оперного формообразования в раннем армянском оперном творчестве.

Объект - композиционно-жанровые и интонационно-стилевые черты оперы А. Тиграняна «Ануш».

Научная новизна состоит в применении специфического ракурса анализа оперы А. Тиграняна «Ануш».

Методологическая основа исследования заключается в диалогическом подходе и опирается на преломление концепции диалога М. Бахтина в научных исследованиях А. Самойленко и Бай Цюаня.

Основное изложение материала. Армянский музыкальный театр имеет давние корни, уходящие в музыкально-поэтическое творчество гусано-ашугской традиции. Однако профессиональное становление оперного жанра в армянской музыке произошло довольно поздно и ознаменовало собой начало национального профессионального композиторского творчества. 
Явившаяся исторически наиболее ранней национальной оперой ${ }^{1} \mathrm{c}$ ярко выраженным национальным армянским колоритом, «Ануш» Тиграняна стала примером синтеза характерного армянского музыкального мышления, в котором соединились, с одной стороны, типичные для армянского мелоса ритмоинтонационные структуры и жанровобытовые фольклорные элементы, а с другой - установленные и отработанные, даже в некоторой степени уже ставшие не столь актуальными в европейской опере принципы развития оперной драматургии, формообразования и структурирования оперного действия.

Опера «Ануш» существует в нескольких авторских редакциях. Премьерная постановка в первой редакции была осуществлена в 1912 году, постановка оперы во второй редакции - в 1930-е годы. Многие исследователи отмечают, что первая редакция оперы «Ануш» с точки зрения оркестрового решения выглядела несколько примитивно, была лишена ярких гармонических сочетаний, оркестровке не доставало профессионализма, а опере не хватало сквозного драматургического развития.

По этому поводу Беата Навратил пишет, что главной задачей Тиграняна было оставаться «верным своим корням» монодической армянской народной музыки, преломив их в драматической опере. Вопрос инструментовки в некоторой степени оставался открытым, поскольку «армянская традиционная музыка использовала очень немногие или почти ни один из классических инструментов», а также несоответствие объема мелодической основы народных песен драматическим объемам оперы $[12,121]$.

Из биографических данных о А. Тиграняне известно, что композитору пришлось самостоятельно совершенствовать и оттачивать свое мастерство симфонического мышления и техники на протяжении всей жизни. Поэтому вторая редакция по сравнению с начальной оказывается более отточеной именно в оркестровом плане. Примером тому может служить замена сценического пролога, присутствовавшего в первой редакции, вокально-симфонической увертюрой во второй. Большее развитие получила лейтмотивная и лейтинтонационная система - следуя лучшим оперным традициям, А. Тигранян вводит во вступление основные музыкальные темы, характеризующие главных героев и отношения между ними - это лейтсферы лейттемы адата, Ануш и Саро.

По мнению К. Авдалян, недостаток профессионализма в опере «Ануш» был компенсирован проявлением национального армян- 
ского колорита, выразившегося в великолепном знании армянского фольклора, ашугских традиций, пастушеских наигрышей, армянских причетов и заплачек. Кроме того, по мнению исследователя, «недостаточный профессионализм А. Тиграняна делал его творчество открытым к новым, необычным музыкальным явлениям в Россиии в Европе» [2, 234].

Поэтому, отталкиваясь от второй, более зрелой редакции «Ануш», можно проследить степень взаимодействия и влияния устоявшихся европейских традиций на авторское художественное мышление А. Тиграняна.

Природа жанра оперы представляется как диалогическая, поскольку предусматривает все виды диалога в музыке. Бай Цюань в работе «Оперная мелодия как художественно-коммуникативный и интонационно-стилистический феномен» указывает на то, что посредством диалогического подхода можно обнаружить важность содержательно-смыслового функционального обмена внутри оперной композиции, его значение для обособления мелодического словесно-музыкального плана, а также установить определенную функциональную иерархию художественно-выразительных компонентов жанровой формы оперы [4, 35].

А. Самойленко в монографии «Музыковедение и методология гуманитарного знания. Проблема диалога», отталкиваясь от концепции диалога М. Бахтина, обособляет следующие виды диалогической коммуникации:

- диалог согласия, проявляющийся как диалог с традицией культуры в целом;

- диалог разногласия, допускающий встречность суждений, межавторский диалог;

- диалог глухих, основанный на закрытости точек суждения и сопровождающийся непринятием межиндивидуальных художественных позиций;

- диалог молчания, межкультурный (межобщностный, межобщинный) диалог, который представляется исследователю как диалог молчания [6, 82 и далее].

Развивая эту мысль о различении функций диалога, Бай Цюань отмечает: «В жанровой форме оперы в процессе ее исторического развития реализуются все виды диалогической коммуникации, соотносимые с основными планами оперной композиции и/или с основными уровнями актантной модели. Такой диалогический универ- 
сализм оперы обеспечивается ее композиционной вариантностью, масштабностью художественного синтеза и относительной образноэстетической свободой - как свободой выбора эстетической идеи и ее образных соответствий» $[4,33]$.

Попробуем выявить, какие уровни диалогической коммуникации отображают взаимодействие традиционных художественных позиций в опере «Ануш».

Характерной чертой армянской профессиональной музыки является опора на фольклорные и религиозные жанровые традиции, ей не чужды как танцевальные, так и песенные черты, религиозная и светская ритуализация и театрализация. Тематика армянского фольклора вобрала в себя множество исторических фактов и событий, которые нашли отображение в содержательно-интонационной составляющей армянской музыки.

Народные армянские певцы, именовавшиеся випасанами (начиная с I в. до н.э. до VI века н.э.), гусанами (VI в. - XVIII в.) и ашугами (начиная с XVII в.), были представителями фольклорного направления армянского творчества, в котором синтезировались традиции персидских, османских, азербайджанских и грузинских особенностей.

Каждый из трех представителей армянской культурного наследия являлся пропагандистом светского творчества, в котором отображались основные актуальные тематические направления, близкие армянскому быту на каждом историческом отрезке времени.

Так, випасаны явились основателями музыкально-поэтической формы, в которой нашли выражение основные религиозные и мифологические мировозрения. Гусаны, культивируя эту устную форму искусства, расширили ее жанровую основу в направлении лирического и эпического содержания. Сферой применения данного музыкально-поэтического направления народного армянского творчества стали преимущественно свадьбы, похороны и всевозможные народные празднования. Исполнения песен гусанов характеризовались наличием музыкального инструментария, а также определенной театрализацией, обусловленной сакральным смыслом сопровождаемого события.

В период XVII-XVIII веков на смену гусанам приходят ашуги, музыкально-поэтическое творчество которых уже отчасти становится фиксированным. Ашуги - самостоятельный, более развитый в своем социальном предназначении тип народного певца-сказителя, являвшегося поэтом, композитором и исполнителем в одном лице. Несмо- 
тря на то, что армянские ашуги отдавали предпочтение первенству текстового содержательного начала, которое, собственно говоря, и фиксировалось, музыкально-интонационная составляющая опиралась на импровизированные мотивы, нередко с сопровождением народного инструмента. Творчество ашугов представляется синкретичным направлением народного творчества, которое вышло на уровень профессионального. Об этом свидетельствует традиция состязаний ашугов, в которых побеждал тот, кто обладал наивысшим уровнем художественного мастерства.

Невольно прослеживается параллель со средневековой традиций трубадуров, труверов, миннезингеров и минестрелей, творчество которых было распространено в европейских странах значительно ранее. Аналогично ашугам основной составляющей их творчества была музыкальная импровизация на сочиненный словесный текст, а уровень мастерства данной импровизации представлялся на творческих турнирах-поединках (эта историческая культурная традиция запечатлена в опера Р. Вагнера «Мейстерзингеры»).

Таким образом, армянские национальные певцы-поэты обеспечили связь между двумя областями армянского творчества - народным и профессиональным. Тематическое ядро их поэтическопесенной традиции составляли исторические события, бытовые зарисовки, религиозная тематика, а также немаловажное место занимала любовная лирическая тематика, поэтому творчество гусанов и ашугов и затронуло все существующие жанровые сферы музыкального творчества - эпическую, драматическую и лирическую. Последняя, как проявление кантиленности, в наибольшей степени раскрывается в мелодическом и ритмо-интонационном параметрах как в народной музыке, так и в творчестве профессиональных композиторов.

Опера А. Тиграняна «Ануш» ярко отображает описанные выше традиции певцов-ашугов, которые проявляются как на уровне литературной содержательности произведения, что выражается в выборе материала для либретто, так и на уровне музыкально-интонационной содержательности.

А. Тигранян использовал метод вживания в фольклорный стиль, позволяющий создавать авторский музыкальный материал, неотличимый от образцов народно-песенного творчества. Именно поэтому опера «Ануш» была сразу воспринята современниками как исконно фольклорная музыка. 
Песенный мелос с его интонационной основой преобладает в музыкальном материале оперы и, без сомнения относится к сильнейшим проявлением авторского композиторского стиля в опере. Не используя прямых цитат, А. Тигранян создает типичные для армянских народных песен ритмо-интонационные обороты, которые умело соединяются с типичными для классической европейской оперной традиции формообразующими принципами.

По мненю К. Авдалян, «Ануш» А. Тиграняна «опиралась на живые традиции народной армянской музыки и в меньшей степени апеллировала к европейским оперным традициям. Именно это произведение следует считать настоящим истоком армянского национального оперного искусства» $[2,231]$.

Тем не менее, заметим, что на основе армянских народно-песенных, танцевальных структур и интонаций А. Тигранян выстраивает крупные оперные формы - арии, ансамбли, хоровые сцены, а также сквозные по принципу организации драматургические разделы оперы. Так арии в опере «Ануш» выполняют традиционную для европейской и русской оперы функцию раскрытия внутреннего мира героев, рассказа об их переживаниях и чувствах. Примером перерастания куплетной песенной формы в оперную арию, построенную по принципу вариационного изложения, может служить песня Ануш об ивушке из первого акта «Ива, говорят» («Асу мен урин»), где каждый новый куплет, видоизменяясь и драматизируясь, передает развитие душевых переживаний девушки; а также ария Саро из пятого акта «Высокие горы» («Барцр сарер»), где на основе импровизационного изложенных мелодических построений, соединяющих как распевность, так и речитацию, выстраивается развернутая ария с элементами da саро и развернутой оркестровой интродукцией.

Ансамбли в опере выступают средством выражения взаимоотношений основных героев оперы. Так, например, дуэтные номера присутствуют почти в каждом действии оперы: восторженный, полный любовной лирики дуэт Ануш и Саро в первом действии, дуэтные реплики Саро и Моси во втором действии, дуэт Ануш и Саро в четвертом действии, наполненный тревожным предчувствием, чему способствуют проведения лейтмотивов Саро, Ануш и хоровой темы из второго действия «Амбарцум яйла», напоминающей о сцене гадания.

Хоровые сцены созданы в лучших традициях европейского оперного театра и олицетворяют собой народную массу в опере, которая, как и принято, противопоставляется личностному миру основных 
героев. Так, например, второе действие представляется ярким примером традиционного выстраивания развития оперного действия, сочетающегося с характерным проявлением национально-стилевого мышления композитора. Это действие является драматургическим центром оперы, а его формообразующая составляющая решена композитором многоуровнево.

Первым уровнем являются хоровые рефрены «Амбарцум яйла», эмоциональный окрас которых модулирует от светлого, радостного, приподнято-праздничного характера в сторону печальных настроений, с оттенком трагичности, предсказывая тем самым фатальный исход завязавшихся на фоне народного празднования событий. Хор в данном случае оказывается одновременно свидетелем, комментатором и непосредственным участником событий.

Второй драматургический уровень - это партии основных героев Саро, Моси и Ануш, которые тесно взаимодействуют с образами народа, вступают с ними в диалог. В лучезарных приподнятых интонациях в партии Моси ощущается тревожность, которую вносят интонации лейтмотива адата, подготавливая зрителя-слушателя к трагическим событиям четвертого и пятого актов.

Но наиболее ярким эпизодом оперы с точки зрения драматургического развертывания музыкального материала представляется сцена гадания, в которой задействованы и хоровая и сольная драматургические сферы. Их пересечение происходит внезапно - в одном из куплетов происходит резкая смена общего приподнятого настроения Саро (возлюбленному Ануш) предсказывают гибель - что влечет за собой поворот сюжетного плана.

Типичным для европейского мышления рубежа XIX-XX веков является использование системы лейтмотивов. Одним из основных является лейтмотив адата, своеобразной темы рока в армянской интерпретации, он олицетворяет душевные страдания героев и неизбежность трагической развязки. Он звучит в партии Моси во втором действии, в сцене борьбы Саро и Моси в третьем действии. С ним интонационно тесно связан лейтмотив поражения Моси, который встречается в четвертом действии в дуэте Саро и Ануш, а также в арии Моси.

Другая, противоположная теме адата сфера лейтмотивов, - это лейтмотивы Ануш и Саро, которые могут быть интерпретированы как темы трагической любви. Так лейтмотив Ануш появляется в первом действии в партии Ануш, в конце второго действия, после пора- 
жения Моси в третьем действии, в четвертом действии в дуэте Саро и Ануш. Лейтмотив Саро встречаем в песне Ануш в первом действии, в сцене гадания во втором действии, в предшествующих четвертому действию и завершающих пятое действие и оперу в целом оркестровых фрагментах.

Приближен к лейтмотиву и материал хора «Амбарцум яйла» из второго действия, который меняет свою эмоциональную окраску, образует тематическую арку - становится материалом средней части дуэта Саро и Ануш в четвертом действии, а в финале оперы представлен как скорбное, траурное a capella.

Для драматургической концепции оперного спектакля А. Тиграняна важными оказались именно интонационные переклички и единство тем, для того чтобы «песни, составляющие музыкальную основу оперы «Ануш», складывались в целостную музыкальную драматургию, образуя систему лейтмотивов, легко узнаваемых даже малоподготовленными слушателями» [2, 235].

Таким образом, в опере «Ануш» соединились два традиционных для разных культур - европейской и восточной - художественных принципа, которые заложили основу для дальнейшего расцвета профессионального композиторского творчества.

Согласно философскому словарю, под традицией понимается передача из поколения в поколение элементов культурного наследия, которые сохраняются в определенных обществах, классах и социальных группах в течение длительного времени, охватывающих нематериальные и духовные ценности [10, 692].

В музыкальном творчестве транслятором традиционного в наибольшей степени, без сомнения, является народная музыка. «Как и культура в целом, народная музыка семиотически неоднородна, она взаимосвязана не только с другими видами искусства, но и с разными сферами культуры. Более того, она вступает с ними в диалог, обмениваясь своими информационными ресурсами» [3, 22].

Выводы. Художественный синтез, осуществленный А. Тиграняном в опере «Ануш», представляется как некоторое коммуницирующее явление двух противоположных традиций, двух типов музыкально-художественного мышления, которое можно охарактеризовать одновременно как диалог согласия, проявляющийся как отношение композитора к традиционному пониманию армянской культуры, и диалог разногласия, благодаря которому композитор смог привлечь ранее нетипичные для авторского мышления А. Тиграняна принци- 
пы оперной архитектоники и драматургической организации музыкального материала.

Таким образом, проведенный анализ позволяет утверждать, что «Ануш» Тиграняна, несмотря на номерную структуру строения, обладает тенденцией к непрерывной развертываемости оперной композиции, наличие в вокальных партиях оперных героев сугубо национально-армянской интонационной основы способствует слиянию ариозных и речитативных жанровых сфер, а наличие лейтмотивной системы позволяет предположить определенное композиторское стремление усилить симфоническую составляющую данного оперного произведения, что несмотря на «ранний профессионализм», характеризующий данное произведение, обнаруживает его тяготение к актуальным тенденциям европейского оперного творчества конца XIX - начала XX столения.

\section{ПРИМЕЧАНИЯ}

${ }^{1}$ Исторически первым армянским оперным произведением является «Аршак Второй» П. Чухаджяна, написанное в последней четверти XIX века. Однако армянской оперу можно назвать лишь благодаря ее сюжету. Музыкальная сторона больше соответствует традициям итальянского оперного театра [2].

\section{СПИСОК ЛИТЕРАТУРЫ}

1. Авдалян К. Национальный стиль в армянской музыкальной культуре XX века. автореф. дис. ... канд. искусствоведения: 24.00.01. Москва, 2011. 29 с.

2. Авдалян К. Рождение армянской национальной оперы в контексте диалога культур. Вестник РГГУ. Серия: История. Филология. Культурология. Востоковедение. 2008. № 10. С. 230-240.

3. Ануфриева Н. Народная музыка в контексте философского осмыления традиционной художественной культуры. Исторические, философские, политические и юридические науки, культурология и искусствоведение. Вопросы теории и практики. 2011. № 5-4. С. 21-24.

4. Бай Цюань. Оперная мелодия как художественно-коммуникативный и интонационно-стилистический феномен: дис. ... канд. искусствоведения: 17.00.03. Одесса, 2017. 185 с.

5. Зурабян Ж. Национальное своеобразие тематизма в армянской симфонической музыке первых послевоенных лет: дис. ... канд. искусствоведения: 17.00.02. Ереван, 1985. 210 с.

6. Самойленко А. Музыковедение и методология гуманитарного знания. Проблема диалога. Одесса: Астропринт, 2002. 244 с.

7. Саркисян С. Интегрирующие процессы в армянской музыке. Lpupłp

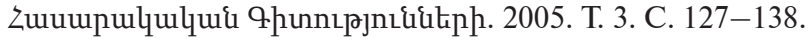


8. Саркисян С. Армянская музыка в контексте XX века: дис. ... доктора искусствоведения 17.00.02. Ереван 1999. 343 с.

9. Тигранов Г. Армянский музыкальный театр. Ереван, 1956. 383 с.

10. Философский энциклопедический словарь / сост: Л. Ф. Ильичев, П. Н. Федосеев, С. М. Ковалев, В. Г. Панов. Москва: Сов. Энциклопедия. 1983. C. 692.

11. Шавердян А. Очерки по истории армянской музыкти XIX-XX веков. Досоветский период. Москва: Государственное музыкальное издательство, 1959. $448 \mathrm{c}$.

12. Navratil B. Music in poetry and poetry in music: Tumanian's «Anush». Candidate'sthesis / City University of New York, 2015. 177 c.

\section{REFERENCES}

1. Avdalyan, K. (2011) National style in the Armenian musical culture of the 20th century. Candidate's thesis. Moscow [in Russian].

2. Avdalyan, K. (2008). The birth of the Armenian national opera in the context of the dialogue of cultures. Herald of the RSUH. Series «History. Philology. Culturology. Oriental Studies. № . 10. p. 230-240 [in Russian].

3. Anufrieva, N. (2011). Folk music in the context of philosophical interpretation of traditional artistic culture. Historical, philosophical, political and legal sciences, culturology and art history. Questions of theory and practice.. № . 5-4. p. 21-24 [in Russian].

4. Bai Quan (2017). Opera melody as the artistic and communicative and intonation and stylistic henomenon. Candidate'sthesis. Odessa [in Russian].

5. Zurabyan, J. (1985). National originality of themes in the Armenian symphonic music of the first post-war years. Candidate'sthesis. Yerevan [in Russian].

6. Samoylenko, A. (2002). Musicology and methodology of humanitarian knowledge. The problem of dialogue. Odessa: Astroprint [in Russian].

7. Sargsyan, S.(2005). Integration processes in Armenian music. Lraber Hasarakakan Gitut'yunneri. Vol. 3. p. 127-138 [in Russian].

8. Sarkisyan, S. (1999). Armenian music in the context of the twentieth century. Doctor's thesis. Yerevan [in Russian].

9. Tigranov. G. (1956). The Armenian Musical Theater. Yerevan [in Russian].

10. Philosophical Encyclopaedic Dictionary (1983). Originators: L. F. Ilyichev, P. N Fedoseev, S. M. Kovalev, V. G. Panov. Moscow: Sov. Encyclopedia. c. 692 [in Russian].

11. Shaverdyan. A.(1959). Essays on the history of Armenian music of the XIXXX centuries. Pre-Soviet period. Moscow: Gosudarstvennoe muzyikalnoe izdatelstvo [in Russian].

12. Navratil, B. (2015). Music in poetry and poetry in music: Tumanian's» Anush». Candidate's thesis. City University of New York [in English].

Стаття надійшла до редакції 22.03.2017

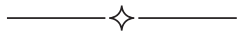

